\title{
The evolution of public health ethics frameworks: systematic review of moral values and norms in public health policy
}

\author{
Mahmoud Abbasi $^{1} \cdot$ Reza Majdzadeh $^{2} \cdot$ Alireza Zali $^{3} \cdot$ Abbas Karimi $^{4} \cdot$ \\ Forouzan Akrami ${ }^{1}$
}

Published online: 9 November 2017

(C) Springer Science+Business Media B.V., part of Springer Nature 2017

\begin{abstract}
Given the evolution of the public health (PH) and the changes from the phenomenon of globalization, this area has encountered new ethical challenges. In order to find a coherent approach to address ethical issues in PH policy, this study aimed to identify the evolution of public health ethics (PHE) frameworks and the main moral values and norms in $\mathrm{PH}$ practice and policy. According to the research questions, a systematic search of the literature, in English, with no time limit was performed using the main keywords in databases Web of Science (ISI) and PubMed. Finally, the full text of 56 papers was analyzed. Most of the frameworks have common underpinning assumptions and beliefs, and the need to balance $\mathrm{PH}$ moral obligation to prevent harm and health promotion with respect for individual autonomy has been specified. As such, a clear shift from liberal values in biomedical ethics is seen toward the community's collective values in PHE. The main moral norms in PH practice and policy included protecting the population against harm and improving PH benefits, utility and evidenced-based effectiveness, distributive justice and fairness, respect for all, privacy and confidentiality, solidarity, social responsibility, community empowerment and participation, transparency,
\end{abstract}

Forouzan Akrami

froozan_akrami@yahoo.com

1 Medical Ethics and Law Research Center, Shahid Beheshti University of Medical Sciences, Tehran, Iran

2 Community Based Participatory Research Center and Knowledge Utilization Research Center, Tehran University of Medical Sciences, Tehran, Iran

3 Functional Neurosurgery Research Center, Shohada Tajrish Neurosurgical Center of Excellence, Shahid Beheshti University of Medical Sciences, Tehran, Iran

4 Faculty of Law and Political Science, University of Tehran, Tehran, Iran accountability and trust. Systematic review of PHE frameworks indicates utilization of the aforementioned moral norms through an practical framework as an ethical guide for action in the $\mathrm{PH}$ policy. The validity of this process requires a systematic approach including procedural conditions.

Keywords Public heath $\cdot$ Health policy $\cdot$ Morals/ethics · Justice

\section{Introduction}

Public Health Ethics (PHE) is a relatively new field of bioethics, and is related to moral implications of a wide range of activities aimed at maintaining and improving the population health. PHE is an area that includes both moral and real issues in health policy and health science. With increasing growth of risk factors, infectious disease threats and chronic health problems such as diabetes and obesity, policy makers, Public Health $(\mathrm{PH})$ professionals and community stakeholders should address complex moral conflicts of $\mathrm{PH}$ practice (Childress and Bernheim 2015).

According to the classic definition of Institute of Medicine, the PH is what we as a society collectively do to ensure the conditions in which the public can live healthy. The definition indicates a collective effort, but at the same time refers to ensuring of the conditions in which the public could live healthy. We started with activity, but the topic is inevitably tied with the PH goals such as empowerment of healthy people in healthy communities (Institute of Medicine 2003; Childress and Bernheim 2015).

$\mathrm{PH}$ authorities for prevention of disease, disability and death are faced with numerous decisions. Although the $\mathrm{PH}$ is an important ethical measure with moral foundations, yet some of its interventions threaten other moral norms such 
as autonomy, privacy and confidentiality. It has been widely acknowledged that answering ethical questions on PH needs a different approach than traditional medical ethics (Kass 2001). The primary and classic goal of PH includes disease prevention rather than treatment of disease; unlike medical practice that is related with patients' treatment, $\mathrm{PH}$ performance focuses on the health of the population. Because of the differences between clinical and $\mathrm{PH}$ practice, application of ethical principles in these two areas is different. According to $\mathrm{PH}$ focus on the prevention, this area has always been faced with dilemmas of appropriate scope of its achievement and moral interference of its activities with personal freedom (Faden and Shebaya 2016).

$\mathrm{PH}$ is not only the traditional function of government to protect the public against imminent threats, but at a basic level, it is cooperative behavior and trusting relationships in the communities, and as much as a wide agenda to address complex social, behavioral and environmental conditions affecting health. American Public Health Association has defined 10 essential functions for effective implementation (APHA 2014), which is the reason for the variety of the theoretical and practical frameworks that have been suggested over time for PHE. In order to find a coherent approach to address ethical issues in $\mathrm{PH}$ policy and practice, we systematically reviewed ethical frameworks of $\mathrm{PH}$ with the aim of identifying the evolution of PHE frameworks and the main moral values and norms in $\mathrm{PH}$ area.

\section{Methods}

Argument-based systematic reviews have been introduced as a more valid manner than informal or simple reviews to improve ethical decisions in healthcare, health system research or PH policy that resulted in a sound policy-making (Strech and Sofaer 2011). In this study, we act based on the suggested model by Strech and Sofaer for writing systematic reviews of argument-based literature through the following steps:

1. Formulating the research question and eligibility criteria.

2. Searching and screening related literature which meet eligibility criteria.

3. Analyzing and synthesizing data.

4. Extracting and presenting results in line with the research question.

\section{Research question and eligibility criteria}

The research question was that which ethical approach should be used in PH policy? More precisely, which ethical principles and moral norms must be taken into consideration to build a framework for ethical evaluation of $\mathrm{PH}$ policy and practice?

The eligibility criteria included:

1. A publication, if; it was a peer-reviewed, published academic articles or books; international or national-level reports of official bodies; or $\mathrm{PhD}$ theses. Editorials and commentaries are considered to be excluded from the study.

2. A targeting a $\mathrm{PH}$ policy or program or intervention, and B. providing a set of moral norms; ethical principles or a theoretical or practical framework for ethical analysis of a $\mathrm{PH}$ policy, program or intervention.

\section{Search strategy}

A systematic search of literature, in English, with no time limit up to 20 July 2017, was performed using the following keywords in Web of Science (ISI), and PubMed databases and also WorldCat Dissertations, that were selected based on the main terms in the study questions.

\section{PubMed search}

("Public health/ethics" [MeSH Terms] OR "public policy/ ethics" [MeSH Terms] OR "public health administration/ ethics" [MeSH Terms]) NOT "research" [MeSH Terms] AND ("ethics/standards" [MeSH Terms] OR "normative ethics" [MeSH Terms] OR "ethical analysis" [MeSH Terms] OR ethical framework) NOT "clinical trials as topic/ethics" [MeSH Terms] AND “english" [Language].

\section{Web of science search (ISI)}

TOPIC: ("public health ethics"*framework) $O R$ TOPIC: (public health research*health policy) AND TOPIC: ("ethical framework") AND TOPIC: (English).

Timespan: All years. Indexes: SCI-EXPANDED, SSCI, CPCI-S, CPCI-SSH, ESCI.

Totally, 251 papers were retrieved. References retrieved from these two databases were imported into bibliographic software (Endnote X7). Owing to duplication of 28 cases, after removing 14 repeated cases, 237 papers remained and their abstracts were reviewed by two researchers. For paper selection between the two researchers, $79 \%$ agreement was found. There was disagreement in $18 \%$ of cases that the text of the paper was studied and under the opinion of research supervisor, the agreement reached $100 \%$. In order to ensure complete coverage of ethical frameworks, in addition to 45 selected papers, their references, notes and bibliographies were studied (snow ball search) and 11 relevant papers were added. The Google scholar search engine was used to complete search coverage (Greenhalgh and Peacock 2005). 
Finally, the full text of 56 papers that met eligibility criteria was studied and analyzed (Fig. 1).

\section{Results}

The 56 PHE frameworks have established some of the moral theories and/or ethical principles and/or some steps for evaluating a PH program/intervention/policy (Table 1). The type of papers included 49 analytic or review articles, five papers of official bodies, and two qualitative studies. According to the study purpose while reviewing the underpinning theory or philosophy of the frameworks, we focused on the fundamental principles and values and practical criteria.

\section{Typology of the PHE frameworks}

We categorized the reviewed frameworks into the two groups: theoretical or conceptual which has been presented as a theory or a set of ethical principles or broad norms and practical frameworks which has been discussed on how to

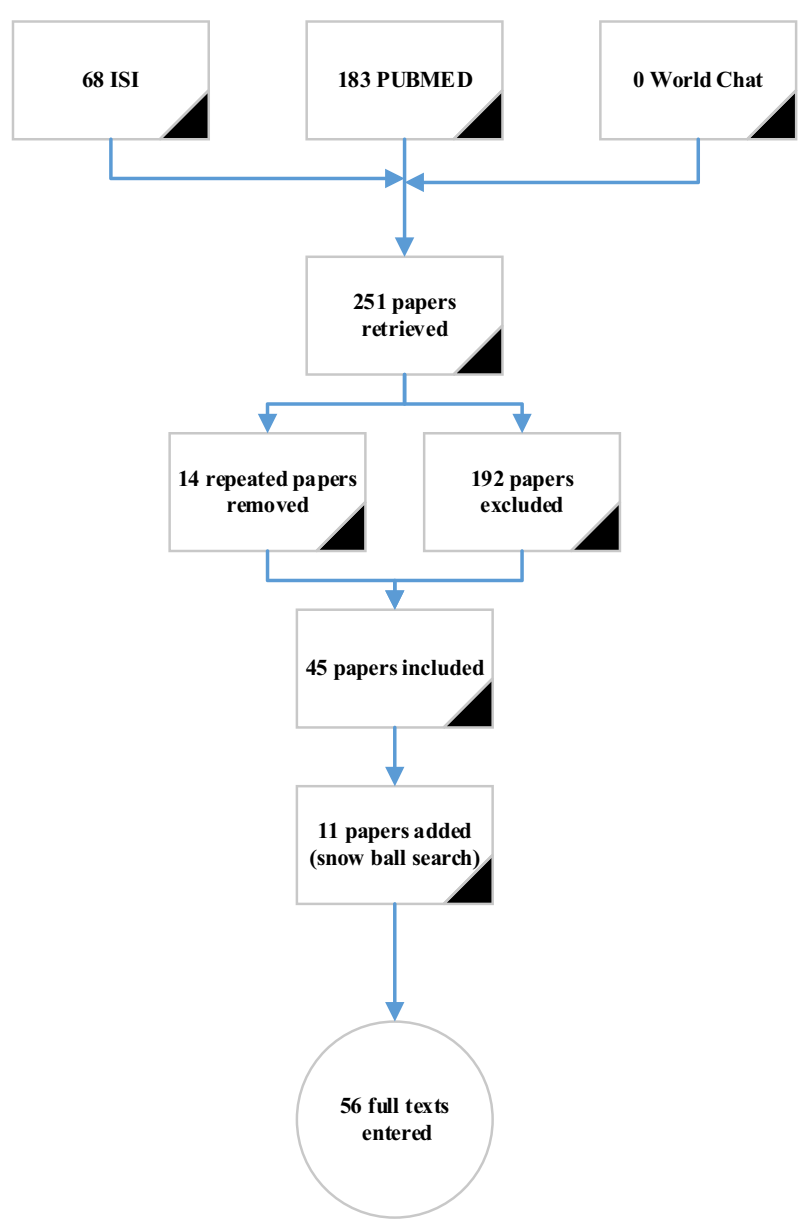

Fig. 1 Flow diagram of systematic search apply the ethical principles and moral norms in $\mathrm{PH}$ practices or policies. Although, some practical frameworks have outlined certain principles and values, these values have not come along with an overarching moral theory, and they were not attempted to provide a comprehensive philosophical approach, however in part, have been derived from implicit or explicit normative views. Finally, 23 theoretical frameworks and 33 practical frameworks were identified.

\section{Underpinning theories and philosophies of PHE}

Two main concerns have led to the formation of PHE frameworks; overcoming of the public interests over individual liberty and autonomy, and priority setting and allocation of scarce resources, especially in developing countries, which has risen the discussion of justice. Most of these frameworks had common underpinning assumptions and beliefs. The need to balance between PH moral obligation of preventing harm and health promotion with respect for individual autonomy has been specified so that a clear move of liberal values in biomedical ethics is seen toward the community's collective values in PHE. Some of the scholars have proposed quitting clinical ethics approach because of differences of these two areas (Kass 2001). In 1997, Yan-Guang Wang reported inadequacy of principlism framework, especially for shaping an effective and ethical policy to deter the HIV epidemic in china. He suggested that an improved bioethical framework would include principles of tolerance, autonomy, beneficence, and care for and care about in which tolerance and care should play a key role because of interdependence of humans, although autonomy and care will be in conflict (Wang 1997). Nancy Kass was the first American pioneer on $\mathrm{PH}$ thinking who designed a practical framework for PHE, including 6 steps with a target group of the $\mathrm{PH}$ authorities than preferably the philosophers. She is one of the first persons who called PH professionals for moral reasoning based on both facts and values. While referring to the inadequacy of biomedical ethics framework to support the needs of PHE, she proposed a framework based on two key values of rights and social justice. By emphasizing positive rights, in addition to negative rights, she pointed out the duty of the state to protect the public from harm and promote PH (Kass 2001).

Childress et al. tried to conceptualize PHE. They investigated the development and effect of different perceptions of the concept of "public" over time, for example, public not only as a numerical population that can be defined and measured, but as a political group defined with obligations, commitments and legal relations, as well as diverse cultural and moral understanding (Childress et al. 2002b). On the other hand, regarding debates raised about priority setting and resource allocation especially in developing countries, ethical frameworks for prioritization in $\mathrm{PH}$ institutions have 


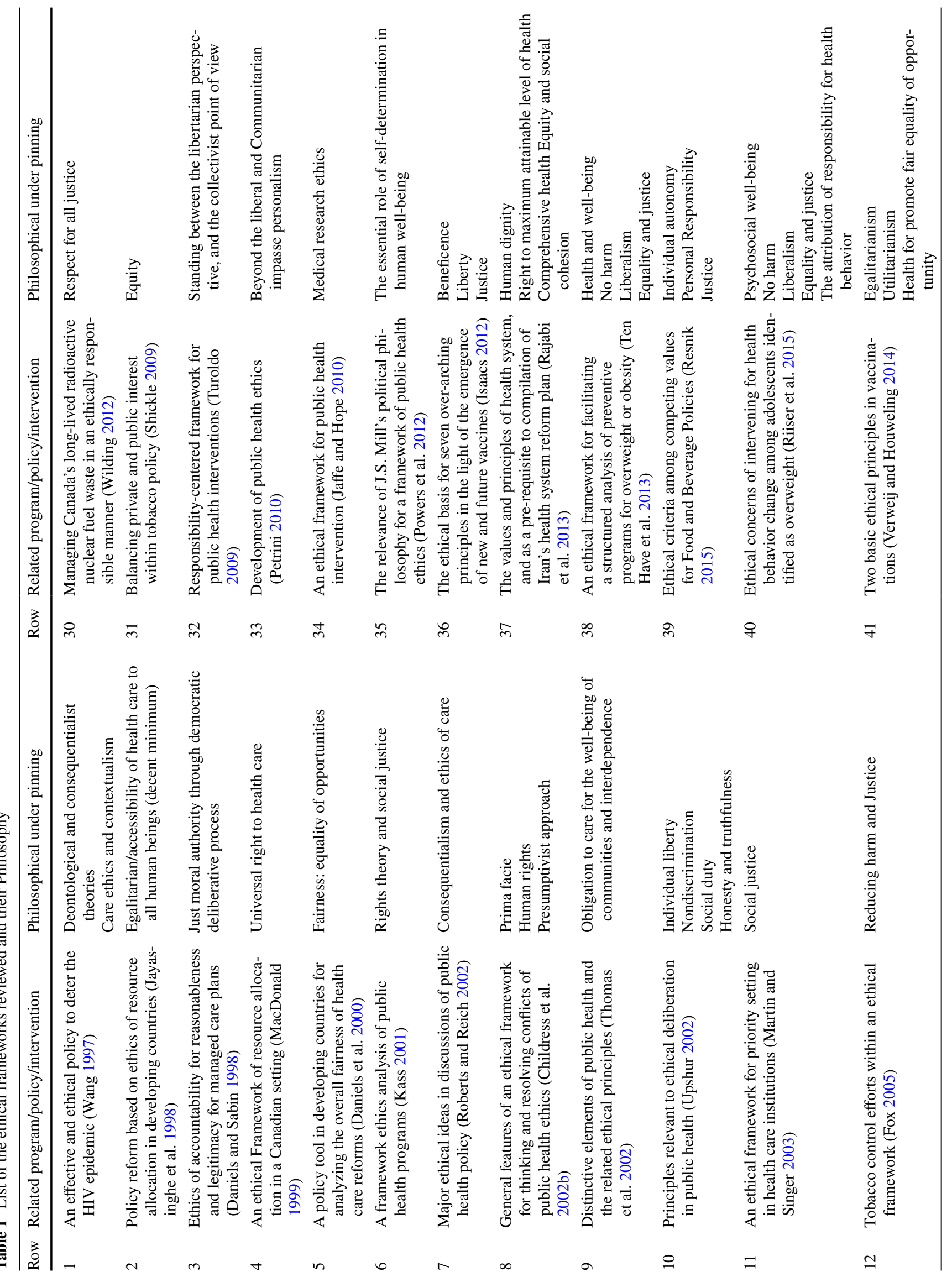




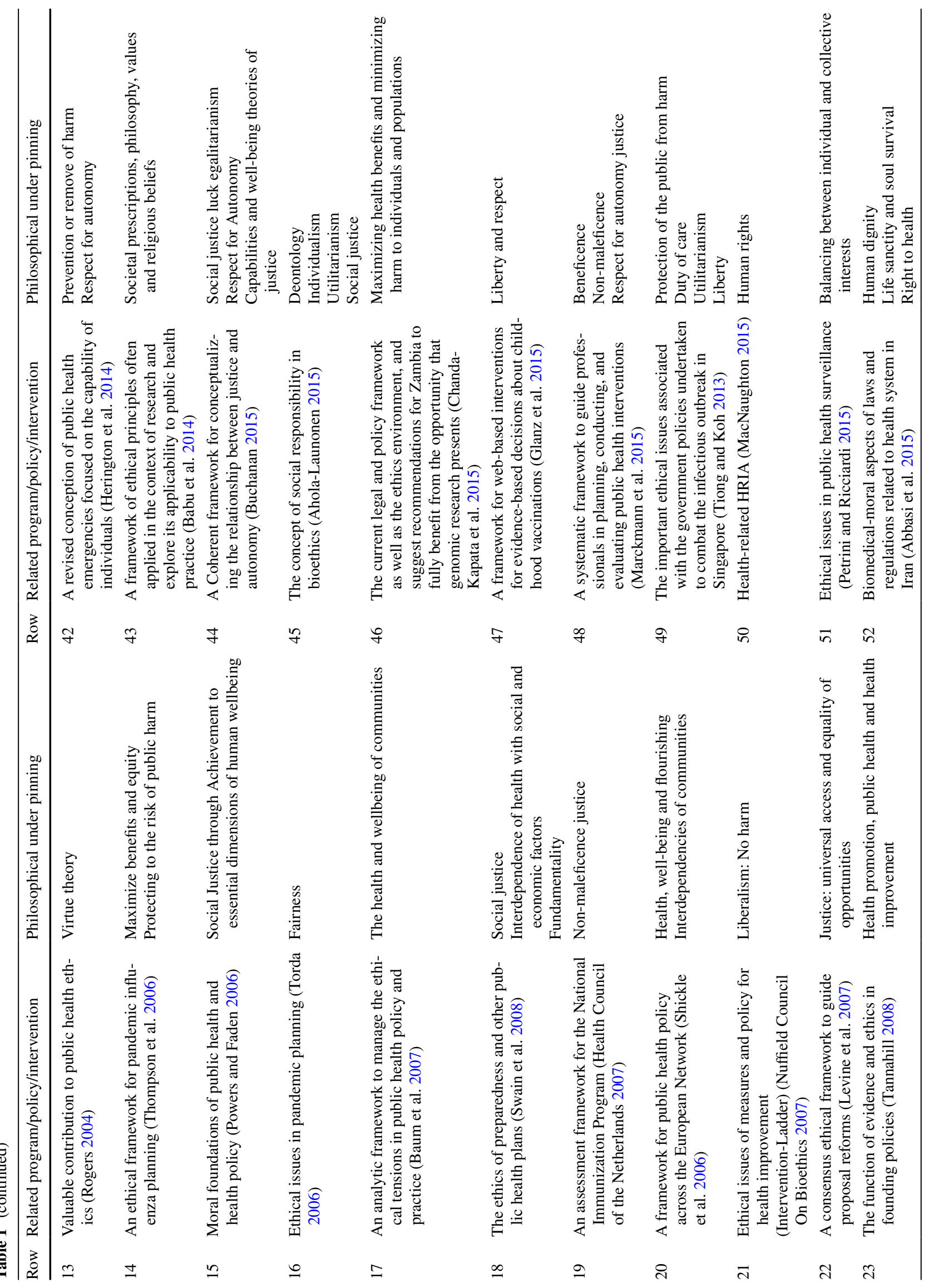




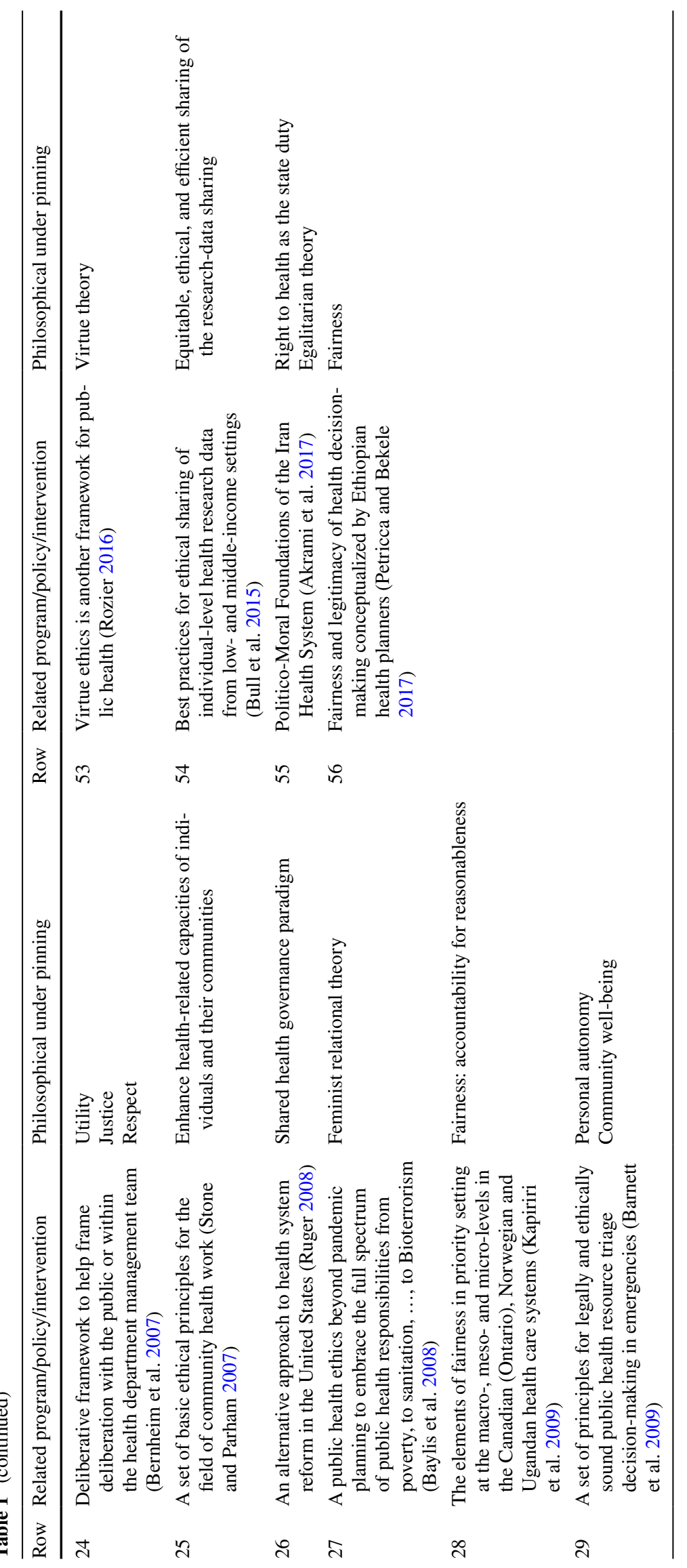


emerged based on the philosophy of social justice. In these frameworks, fundamental values are fairness and accountability for reasonableness. They outlined a combined normative and empirical methods based strategy, and the involvement of all beneficiaries and partners in policy decisions that affect the delivery of health care services (Martin and Singer 2003; Daniels 2000, 2008; Daniels and Sabin 1998, 2008; Daniels et al. 2000). For common knowledge about the inadequacy of biomedical ethics to be used in the field of $\mathrm{PH}$ community, Baylis et al. presented a theoretical framework of relative morality as a feature of PHE treating public as related social beings (Baylis et al. 2008). This theory which was revised in 2010 by the authors, is based on three fundamental values: relative autonomy, relative social justice and relative solidarity Relative autonomy unlike individual autonomy recognizes connection and relevance of the public in terms of economic, social and political conditions serving autonomy through social changes instead of focusing on better protection of individual freedom. Relative social justice, unlike a focus on non-discrimination and distributive justice (distribution of limited goods), emphasizes fair access to social goods including opportunities, rights and power. Focusing on this aspect of justice requires $\mathrm{PH}$ look at moral issues associated with systematic patterns of inequity leading to disadvantages. Finally, relative solidarity, unlike traditional focus on altruism and opposed groups of "us" and "them," emphasizes the inclusion and interaction of "we" (Kenny et al. 2010).

Petrini and Gainottie after reflecting the shortcoming of the principles of biomedical ethics to solve moral dilemmas of public health, considered three common philosophical theories of Communitarianism, Kantian and Utilitarianism in their ethical analysis. Each of these theories were inadequate to be used in PH area and have ignored the key concept of personalism (Petrini and Gainotti 2008). Personalism first in regard to human dignity and second, due to the agency of man as a social being in the construction of the common good through solidarity, has been proposed as a philosophical basis in the health care system (Bielecki and Nieszporska 2016). The primary moral principle in this theory is that all human beings deserve respect. Personalism which originated in health ethics and share common issues with health movement and human rights, emphasizes the protection of the weak and sick, as an inalienable matter and measures moral value as a reflection of others' dignity and well-being. Therefore, it obligates us to make positive efforts. Underpinning values of personalism were extracted from respect for a person, and include autonomy, privacy, justice and equal opportunities in the allocation of health resources. Personalism is a combination of communitarianism (social value and solidarity), and Rawls's views based on the belief that personal goods are the basis of common good (Petrini and Gainotti 2008). However, the communitarians provided little operational guide for the implementation of this approach, but have concluded that considering this theory in answering philosophical questions about the value of human health is very important.

On the contrary, Ahola-Launonen has introduced social responsibility for human health and well-being, and has considered individualism theoretical framework inadequate due to disregarding of social context. He believed that despite authorities act rationally, due to the effect of social determinants of health on chronic diseases related to life style, ethical decisions in health require a social view (AholaLaunonen 2015). Thus, legitimate and fair decision making issue to priority setting in $\mathrm{PH}$ policy led to the formation of the framework of accountability for reasonableness (Daniels 2000) that conceptualized differently by health system stakeholders of developing countries (Petricca and Bekele 2017; Kapiriri et al. 2007, 2009).

Some authors based on virtue theory have emphasized the inclusion of moral virtues in underpinning values of PHE. They believe that for the past several decades, the concept of structure in theological ethics, almost exclusively, has focused on social structures for the need to change. Structures that continue in unfair situations and cause systematic disadvantages to human development are classified as structures of sin and were the goals of social and theological criticism. PH professionals are trying to create new structures that have a positive effect on the life of individuals and communities. The social structures (i.e. law, policy, and environment) are formed by individual characteristics and virtues as an underpinning value making the person's behaviors and habits, and forming them (Karen and Meagher 2011; Rozier 2016). Finally, some frameworks have turned backwards to human rights foundations, by emphasizing on the universal access to minimum decent health care and balancing the PH benefits of a policy against its human rights burdens (MacNaughton 2015).

\section{Broad and narrow moral norms of public health}

The prevention of and protection to harm, and promotion of health benefits were the first broad moral norms that emerged (Table 2). These ethical objectives are placed under the broader principles of beneficence and non-maleficence. $\mathrm{PH}$ is a common good that follows the universal principle of beneficence. Some scholars have described no-harm principle that roots in Mill's thinking as the fundamental principle to justify the limitations of individual freedom against harm to others, and considered it as a basis for protecting the health of populations from disease and death (Powers et al. 2012). By identifying three moral goals of PH, including producing benefits, preventing and removing harms, and producing maximal balance of benefits over harms (utility principle), Childress et al. outlined the general moral 
Table 2 Broad and narrow types of moral norms

Non-maleficence

Be proportional to the risk of public harm

Protection of the public and society against disease and death

Harm principle

Minimizing harm

Do not harm

Prevention of negative health consequences

Beneficence

Do good

Beneficence

Producing benefits

The common good

Beneficence (subsuming non-maleficence)

Benefit from innovation and desired technology

Health care benefits

Public health benefit

Prevention and health promotion

Protection of the public beneficence

Research benefits relevant to health care

Care

Care for and care about

Caring role for both the caregiver and society

Duty of care

Duty to provide care

Government obligation to meet the basic health needs of all citizens

Principle of utility

Producing maximal balance of benefits over harms and other costs

Population-level utility

Utility of data sharing in publicly funded health research

Outweighing the risks by benefits

Any adverse effects are not sufficient to substantially diminish the benefits

Reducing harms and burdens including limitation of individual autonomy

Be proportional to the risk of public harm proportionality

Employ the least restrictive means

Effectiveness

Evidence based effectiveness

Usefulness

Cost-effectiveness

Cost effectiveness and cost utility

Cost-efficiency

Cost-value

Safety and effectiveness

Effective sharing of individual-level data

Assessing alternative options

Favorable risk-benefit ratio

Feasibility and evidence-based effectiveness

Efficiency

Incremental cost-benefit/cost-effectiveness ratio

Safety of services
Table 2 (continued)

Assessing burden of disease, and weighing of risks, benefits and burdens

Respect

Respect for autonomy

Respect for individual rights

Respect through tolerance

Patient and provider autonomy

Respect for professional and civic values

Respect individuals' autonomy and liberty

Equal and substantial respect

Relational autonomy

Liberty to choose

Respect for life in all its forms

Respect for future generations of human beings, other species, and the biosphere as a whole

Respect for peoples and cultures

Respect for life

Self-determination as an essential dimension of well being

Independence

Informed consent

No paternalism

No stigmatization

Respect for social and cultural values

Mutual respect

Protect disabled people from discrimination

Minimizing stigma

Not using of obesity-related stigma

Freedom from discrimination

Respect for persons autonomy

Respect for physical and social environment

Respecting autonomous choices and actions

Respect of community interests

Interventions be applied without discrimination and stigmatization Confidentiality and privacy

Share personally identifiable health information-with the patients' consent where possible

Protection of privacy and confidentiality

Justice

Justice (across groups, regions, and generations)

Social justice (distributive justice and non distributive justice)

Relational social justice

Distributive justice

Procedural justice

Fairness

Distributive justice

Access/equality

Accessibility of health care to all human beings (decent minimum)/

Access and equality of opportunities

Access to care and to reduce certain social inequities

Equal access

Access to research data 
Table 2 (continued)

Financial barriers to access

Non-financial barriers to access

Equal access to high-quality care

Providing universal and comprehensive coverage

Access to the healthcare

Equitable access

Public access to basic care

Access to essential services in addition to health

Equity

Equity-distributive

Equitable financing

Fairly distribute the benefits, burdens, and costs

Fair distribution of beneficence, e.g. among subgroups

Fairly selection for participation in health programs (vulnerable individuals)

Distribution of the intervention's benefits, burdens and risks

The environment, educational and economic opportunity

Protection of vulnerable groups

Prevention of negative health consequences

Targeting vulnerable, disadvantaged populations

Procedural justice

Fairness (to everyone affected and particularly to minorities and marginalized groups)

Fairness and reciprocity in research data-sharing

Fair decision process

Fairness and legitimate decision making

Publicity condition

Relevance condition

Appeals condition

Enforcement condition

Stakeholder inclusiveness

Compensation

Flexibility in the way of important revision and openness with external stakeholders (such as NGO partners)

Provide supports for those with the duty to care

Procedural fairness in decision-making

Fair coverage decisions

Provide fair compensation for volunteers

No fault compensation schemes

Hearing minority views

Democratic procedures

Compensation in the event of harm

Fairness translation of genomic research findings into healthcare

Compensation

Equitable participation

Supporting people affected by adverse effects

\section{Reciprocity}

Ensuring the safety of their workers

Reciprocal responsibilities

Fair reciprocity

Obligations of the healthcare profession and reciprocity
Table 2 (continued)

Empowerment and capacity-building

Public education

Informing to make autonomous decisions

Empowering to make self-determined choices

Informed choice

Professional competence

Competency

Empowerment and engagement

Health-related empowerment

Fostering capabilities, a person's ability to be healthy

Expanded health agency

Strengthen the autonomy of the public to promote the capacity, creativity and vitality of citizens

Creating an environment and structures to facilitate healthy choices

Flourishing society

Creating healthy conditions

Individual capability

Individual responsibility

Personal responsibility

Warning agents of the gravity of risks

Respectful environment

Providing of infrastructure for safe and enjoyable physical activity

Enhancing public understanding

Training health workers in interpersonal communication skills

Capability to reasoning

Capacity to exercise moral autonomy

Capacity-building interventions

Expansion of recreational programs

Improving social structures

Relationship between agency, moral character and social structure

Solidarity

Interdependence

Solidarity

Relational solidarity

Social responsibility and participation

Involvement of decision makers and stakeholders

Community participation

Community engagement

Participation of affected populations

Multi- stakeholder (and community) engagement and deliberation inter-sectoral collaboration

Work collaboratively to establish practice guidelines

Inter-sectoral public health

Contribution to society

Collective responsibility

Community agency

Involvement of parents and other stakeholders

Accountability for reasonableness

Public accountability for resource allocation at the populationbased level 
Table 2 (continued)

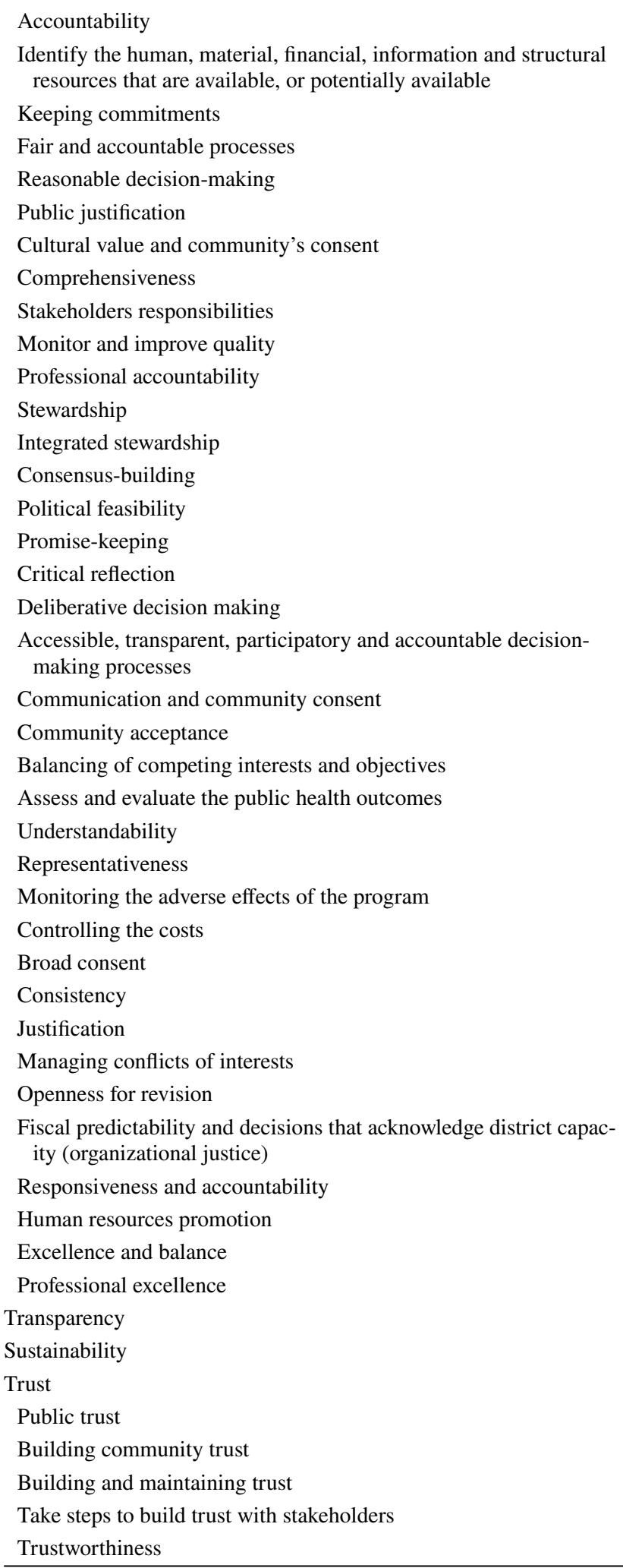

Table 2 (continued)
Community trust
Consent and trust
Critical trustworthiness

This table lists all the mentioned moral norms in public health policies and practices

considerations in $\mathrm{PH}$ that has been introduced and used as a normative basis (Childress 2015; Childress et al. 2002). The evaluation of the benefits of a program requires a precise definition of the objectives and the expected effects of the program, based on sound data and evidence. Sometimes the expected benefits resulted from reduction of risk. For example, a health program may be designed to increase life expectancy (benefit), aimed to reduce the risk factors for premature deaths.

The principle of utility as a broad norm in $\mathrm{PH}$ is defined as the production of maximum balance of benefits of the program on its burdens, including risks, harms, and costs (Childress 2015). Potential harms should be assessed to those who are directly and indirectly affected, and compared with the expected benefits for the target community to determine the maximum benefit. The appropriate actions to manage or minimize the potential risks or inevitable harms is one of the main goals of ethical evaluation.

The other broad norm is respect. Respecting all including self-respect and respect for others is one of the fundamental dimensions of well-being, the adequate level of which is considered necessary to achieve social justice (Powers and Faden 2006). Respect for individual rights and autonomy in most frameworks are emphasized as a right for non-interference (Kass 2001; Childress et al. 2002b; Marckmann et al. 2015; Glanz et al. 2015; Resnik 2015). Lack of observance of the privacy and confidentiality of information, especially in data collection activities and health system research data sharing can bring social and psychological harms to people. Stigma and discrimination are considered as lack of respect (Ten Have et al. 2013). Stigmatization brings about feelings of discrimination and worthlessness, and a sense of identity loss and loosing moral agency, and violates principles of no harm and respect for autonomy. Lee has suggested that PHE requires to interconnect the health of individuals, communities, and environment including other species of life to promote a healthier planet (Lee 2017). Therefore, respect in $\mathrm{PH}$ includes also respect for future generations, other species, and the biosphere as a whole.

Regarding the primacy of the public good and the superiority of collective interests on individual interests in $\mathrm{PH}$ policy, respect for individual autonomy losses its originality. But the necessity for a PH policy or program should be justified and followed by the minimal infringement of 
autonomy, and as such, some scholars have introduced the least restrictions means as a principle. This means that the need for a PH policy or program should be justified with a minimal violation on autonomy. Some scholars have considered six narrow norms of effectiveness, necessity, minimal violation of presumptive values, proportionality, impartiality, and public justification as justificatory conditions for the superiority of norms in conflicting situations (Childress et al. 2002b; Bernheim et al. 2007; Turoldo 2009).

Evidenced-based effectiveness plays a vital role in determining the priority and necessity of a program and its implementation. One of the narrow norms in PH is effectiveness in both financial and non-financial terms. After determining that a proposed compulsory intervention will meet the first three conditions, proportionality requires that restrictions to individual liberty and other conflicting norms should not be exceeded than is necessary to address the level of risk or the need of the community. The sixth condition focuses on the context and resulted in accountability. Context includes specific social, political, and institutional situation in which an action is taken (Childress and Bernheim 2015).

Formal economic analytical methods, including costeffectiveness and cost-benefit analysis, are used as a way to improve decision-making, especially when balancing is required. The cost-effectiveness analysis and calculation of the QALY index (quality-adjusted life years) is mainly used to manage the financial burdens of the health program in order to balance the program's financial impacts. Cost-value analysis is another formal analysis that considers several factors, including the severity of the disease as a social value. In cost-value analysis, unlike the cost-effectiveness analysis, the severity of the disease after intervention is more important than the duration of healing and there is less discrimination against patients who are less likely to be well-off. In such a way, the evaluation of life-expectancy improvement programs for healthy and disabled people is the same. Also, the latter is more ethical, because it takes into consideration the views of the community about the value produced (Nord 1999). By providing systematic, quantitative, and comparative inputs on health interventions, these methods help to make reasonable decisions and are ethically applicable with some limitations (Childress and Bernheim 2015). Efficiency is one aspect of fairness, since inefficient use of resources and ineffectiveness means that some needs will not be met that could have been that resulted in unaccountability (Daniels et al. 2000).

Fairness itself is a broad norm in PH policy that indicates fair distribution of responsibilities, opportunities, resources, benefits and burdens with special attention to vulnerable groups, equal access to primary services and reduction of avoidable inequalities through action on the social determinants of health (Daniels 2008). Another requirement for fairness is compensation, for example, in particular, in cases in which health care workers sacrifice their life, in addition to their assignments (Marckmann et al. 2015). Regarding the duty of care, the norm of compensatory justice is the translation of the principle of reciprocity in the context of PH.

Although there is no specific definition of justice that is unanimously agreed, the term "social justice" is a broad norm and common term in the field of PH (Hofrichter 2003). Social justice, in addition to the distributive justice and procedural justice (ensuring public participation including all individuals, groups and organizations involved, in decisionmaking and implementation of the program), requires fostering of individual capabilities, and development of a sufficient level of the dimensions of human well-being including health, personal security, attachment, respect, reasoning, and autonomy and ability to make informed decisions and right choices (Powers and Faden 2006).

The capabilities approach highlights the important considerations in analyzing the relationship between agency and structure that makes the broad norm of empowerment and capacity-building. Healthy lifestyle is influenced by both individual and social factors affecting health, including structural and living conditions (Cockerham 2005). The concept of diseases relevant to lifestyle and individual responsibility play an important role in the discussions of fair allocation of scarce health care resources. But unhealthy behaviors are not related to mere choice and can be caused by social conditions and inequalities, so that, don't consider as the breach of solidarity (Prainsack 2013).

The formation of emotional bonds and attachments, as well as a sense of solidarity and cooperation with others are prerequisites for the establishment of a just society. Sociologists consider solidarity as a structural issue, which shows how interpersonal communications and interaction between the various components of a society allows for a collective effort to achieve a common good; In other words, solidarity is considered as a moral foundation (Powers and Faden 2006). Solidarity like justice is a broad norm and fundamental value for success in PH programs (Martin and Singer 2003) and means functions reflecting a collective commitment to carry financial, social, and emotional costs to help others (Prainsack et al. 2011). Corporate social responsibility establishes one of the most important applications of the principle of responsibility. Social responsibility for human health and well-being as an inherent aspect of bioethics is not limited only to the commitment towards themselves and other people, but it is deployed to every creature (animate or inanimate) that is involved in life and human progress (Ahola-Launonen 2015). People should be given opportunity to participate in projects that affect their health and well-being (Turoldo 2009). Therefore, community participation and cooperation is a moral norm in $\mathrm{PH}$ context and simply means work with people, rather than on/to people, and is defined as the engagement of community members 
in projects. The first level of community participation is to inform community members about the decisions and activities, the second is to consult with them about proposed activities, and the third is to decide with them, and finally, the highest level of engagement is collaboration in which a partnership with the community is formed and the community members work together to achieve $\mathrm{PH}$ goals as a common good (Wilcox 1994).

Good governance and stewardship through transparency and accountability ensure trust and cooperative behavior, and pursuit of PH goals in the communities. Respect, empowerment, social responsibility, and participation are linked to intermediate outcomes, and the principle of accountability (Tannahill 2008). A fair process allows us to agree on what is legitimate and fair and requires publicity of logical reasons involved in the decision-making. As a common deliberative goal, fair-minded people who seek for mutual justified areas of cooperation must come to an agreement that the logical reasons and evidences are fairly related to meeting health care needs of the society. The principle of transparency requires the involvement of beneficiaries in decision-making, as well as accountable and transparent process, irrespective of the particular interests of individuals and groups. Although, key elements of transparency, relevancy, openness for revision, and regulation to ensure that these conditions are met (regulatory condition) in light of the challenges together have been described to ensure the broad norm of accountability for reasonableness (Daniels 2000). Given the differences in context and the scarcity of resources in developing countries, the concepts reported for responsive prioritizing in health systems at developing countries are involvement and consensus among different stakeholders with different levels of knowledge, skill and expertise, prediction of related financial costs, transparency, flexibility through openness to review with external stakeholders such as NGOs, and evidence-based and needs-based planning, in line with national and international policies based on regional capacity and organizational excellence (Petricca and Bekele 2017; Kapiriri et al. 2007, 2009). Furthermore, consistency, participation and management of conflicts of interests, sustainability, comprehensiveness, and monitoring and evaluation are the other narrow norms provided to ensure accountability (Marckmann et al. 2015).

\section{Commonalities among the frameworks}

First, using a common scientific and deliberative approach for ethical decision-making in $\mathrm{PH}$ plans or interventions has been recommended (Kass 2001; Ruger 2008; Petrini 2010; Carter et al. 2011; Martin and Singer 2003). Ruger has proposed a shared health governance approach in which all individuals, service providers and institutions play a vital role in creating a healthy environment and achieving $\mathrm{PH}$ goals through participation and collaboration (Ruger 2008).

Second, although there is still no common PH moral theory, but in many of these frameworks, fundamental values and underlying assumptions and beliefs are common and the need to balance respect for individual autonomy has been mentioned with moral obligation to prevent harm and promote the community health as the classic goal of PH. Thus, a clear shift is seen from the values of liberalism in biomedical ethics to the community's collective values. Most of the frameworks considered traditional principles of biomedical ethics inadequate for responding to moral issues in $\mathrm{PH}$. Considering human as a social being with respectable common needs requires social justice approach. Therefore, ethics in $\mathrm{PH}$ practice require flourish and strengthen the public autonomy to promote capacity, creativity and vitality of citizens as members of a community (Shickle 2009). MacNaughton in his study emphasizing the use of the method of balancing $\mathrm{PH}$ benefits on human rights burdens, has noted Human Rights Impact Assessment framework progress and challenges remaining in the last 20 years (MacNaughton 2015). Some have argued that $\mathrm{PH}$ should embrace the framework of human rights, because $\mathrm{PH}$ and human rights have a common goal of promoting human flourishing (Annas and Mariner 2016).

Third, in most of the frameworks, common values and norms have been emphasized; collective values and norms such as producing utility, fairness, distributive justice, health equity and reducing social inequalities, solidarity, community empowerment and participation, transparency, accountability, and trust have been added to the implications of protecting of and promoting the population health, and respect for autonomy. Various norms used in different frameworks signify the same concepts, although some of them have not defined applied principles properly, meanwhile the presence of a practical guide for decision-making by practitioners is of special importance. For example, the concept of solidarity in PH should be defined as operational. This term is simply not just an abstract concept meaning altruism. At the normative level, solidarity has a function as a measure of assessing the quality of human relations and is a moral concept (political and social) that is limited to the institutional organization of the community. Solidarity reflects functions of a collective commitment to carry the costs (financial, social, and emotional) to help others (Prainsack et al. 2011).

Fourth, specifying and balancing ethical considerations in $\mathrm{PH}$ are important and done in three ways: making principles and rules and its derivatives (broad and narrow norms), reducing ambiguity and abstraction in these norms and presenting them as a guide for action. Given that midlevel principles are based on common morality and lacks a common moral theory, however, ethical decision-making in $\mathrm{PH}$ is possible by using them with regard to the urgent need 
for PHE practical framework (Coughlin 2008). Childress and Bernheim have introduced a presumptivist framework as the best way to formulate relative weight and strength of conflicting moral norms of PH in a democratic, liberal, and pluralist community. They believe that the assumptions emerged from the main values of a community through the emergence in the constitution, laws, policies and practices, as well as myths and beliefs, all make the public philosophy of the community. Without certainty, they made and should make the criteria of PH interventions. A presumptivist framework places deniable assumptions for concepts and interventions and identifies their denial conditions. Hence, defects caused by two absolutist and contextualist approaches are prevented. On the contrary, it is clearly uncertain, because depending on the situation, individual autonomy or public benefit, each could be prioritized (Childress et al. 2002b; Childress 2015).

And finally, practical frameworks beside a systematic approach, in addition to introducing normative standards and evaluation steps, have proposed procedural conditions for a fair decision-making process and ensuring accountability for reasonableness (Baylis et al. 2008; Thompson et al. 2006; Torda 2006; Marckmann et al. 2015; Ten Have et al. 2013).

\section{Discussion}

Over one decade of adopting the APHA public health code of ethics has elapsed. The code of PHE was made by votes in 2002 under the leadership of PH composed of representatives of several organizations. The goal was to highlight moral principles that follow from $\mathrm{PH}$ characteristics for related institutions. The presence of several moral principles as the code infrastructure is a fundamental belief in the interdependence of humans as essence of the community. This belief is expressed not only in PH efforts to ensure the health of all communities, but also in recognition of the inseparable link between individual health and collective life (Thomas et al. 2002). Although ethical principles in the code provide a useful guide for practical PH decisions, but what the code says does not adequately meet the public justification for $\mathrm{PH}$ policies and actions (Childress 2015).

On the other hand, the phenomenon of globalization and its challenges has led to interdependency of countries in political, economic and environmental aspects and its impact on the health and well-being of humans. Climate change has directly and indirectly affected human health. Climate change has affected the risk and distribution of vector-borne, food-borne and water-borne diseases and also emerging infectious diseases such as Ebola. Managing these changes has produced new ethical challenges such as increasing costs, priority setting, and protecting vulnerable populations. For this reason, scientists, clinicians and $\mathrm{PH}$ professionals have been called to address the practical and ethical aspects of climate change, and health systems need to prevent and manage these effects on population health. At the same time, the need for multiple and multi-setting strategies by other sectors other than health, such as transportation, industry and agriculture, the health impact assessment to identify solutions to reduce the causal agents of climate change and control its health risks, requires inter-sectoral collaboration and community participation (Menne and Bertollini 2005). The issues of susceptibility of some of the sub-populations, access and climate change, and attention to root causes highlight the role of social determinants on health outcomes and health equity. Therefore, although the first code has referred to addressing of the underlying causes of the disease to prevent undesirable health outcomes, issues such as access to care and climate change have created a sense of need to update it (McGill 2015).

Since climate change poses significant global and intergenerational ethical challenges as well as socio-economic burdens and health equity, according to APHA Policy Statement, the new code should guide public health professionals for the advocacy for action, especially among policymakers and other related sectors, prevention and preparedness, education and also conduct research on climate change and health (APHA 2015). Regarding the 2017 them: creating the healthiest nation, APHA Annual Meeting has marked the Climate Change and Health as cornerstone of the year and explained that "everyone has the opportunity to prepare for, protect their families from, and rebuild after a climate event". In addition to targeting the health of the populations, the statement addresses the reduction of health inequalities by focusing on vulnerable groups, such as children, adolescents, and pregnant women, the elderly and marginalized groups (APHA 2017). The process of revising and drafting the new code has now begun, and the important goal of this process is to articulate common values that conduct and improve public health, promote human flourishing based on human rights framework and achieve global justice (Lee et al. 2016).

\section{Conclusion}

Our review shows that a wide diversity of theories has been suggested for PHE. Finding a common approach to address ethical issues in $\mathrm{PH}$ policy requires the convergence of underpinning theories and philosophies of PHE. However, some practical frameworks have outlined certain moral principles and values, even if these values are not accompanied by an overarching moral theory. The evolution of PHE frameworks signifies turning to the collective values and more specified norms such as utility, evidencebased effectiveness, distributive justice and fairness, solidarity and social responsibility, community empowerment 
and participation, transparency, accountability and trust that some of them can be considered as mid-level principles. In addition to distributive justice, what should be considered in developing a PHE framework is considering the achievement of well-being dimensions adequately signifies developing healthy social structures, promoting individual capabilities, developing ability to reasoning and strengthening autonomy based on the theory of social justice.

PHE practical nature requires that we use the aforementioned moral norms through an ethical framework as an ethical guide for action in the PH policy. The validity of this process requires a systematic approach including procedural conditions. Legitimate and fair decision making process requires opportunities to challenge and review decisions in light of a variety of all beneficiaries' considerations including lay members. It allows fair decisions under resource constraints and also facilitates social learning regarding restrictions and links decision-making in health care institutions to wider democratic deliberative processes. Transparency in all aspects leads to strengthening of accountability to communities and their solidarity and trust as a basis for support and sustainability of $\mathrm{PH}$ programs.

Acknowledgements This study is part of PhD thesis in the field of Bioethics that funded by Shahid Beheshti University of Medical Sciences. Authors express their appreciation to the scholars who contributed to this study and for their valuable comments.

\section{References}

Abbasi, Mahmoud, Mehran Seif-Farshad, and Mehrzad Kiani. 2015. Moral Aspects of the Laws and Regulations Governing the Health System in Iran. Trends in Life Sciences 4 (3): 145-153.

Ahola-Launonen, Johanna. 2015. The Evolving Idea of Social Responsibility in Bioethics. Cambridge Quarterly of Healthcare Ethics 24 (02): 204-213.

Akrami, Forouzan, Mahmoud Abbasi, Abbas Karimi, Reza Majdzadeh, Akbar Shahrivari, and Alireza Zali. 2017. Analyzing the Politico-Moral Foundations of the Iran Health System Based on the Theories of Justice. Journal of Medical Ethics and History of Medicine 10: 4.

Annas, George J., and Wendy K. Mariner. 2016. (Public) Health and Human Rights in Practice. Journal of Health Politics, Policy and Law 41 (1): 129-139.

APHA. 2014. 10 Essential Public Health Services. http://www.apha. org/about-apha/centers-and-programs/quality-improvement-initiatives/national-public-health-performance-standards-program/10essential-public-health-services. Accessed 08 Sept 2014.

APHA. 2015. Policy Statement: Public Health Opportunities to Address the Health Effects of Climate Change. Policy Number: 20157. https://www.apha.org/policies-and-advocacy/publichealth-policy-statements/policy-database/2015/12/03/15/34/ public-health-opportunities-to-address-the-health-effects-ofclimate-change. Accessed 03 Nov 2015.

APHA. 2017. 2017 Theme-Creating the Healthiest Nation: Climate Changes Health. https://www.apha.org/events-and-meetings/ annual/why-attend/annual-meeting-theme. Accessed 03 May 2017.

Babu, Giridhara R., Sathyanarayana Tn, Anant Bhan, and J.K. Lakshmi, and Megha Kishore. 2014. An Appraisal of the Tuberculosis Programme in India Using an Ethics Framework. Indian Journal of Medical Ethics 11 (1): 11-15.

Barnett, Daniel J, Holly A. Taylor, James G. Hodge Jr, and Jonathan M. Links. 2009. Resource Allocation on the Frontlines of Public Health Preparedness and Response: Report of a Summit on Legal and Ethical Issues. Public Health Reports 124: 295-303.

Baum, Nancy M., Sarah E. Gollust, Susan D. Goold, and Peter D. Jacobson. 2007. Looking Ahead: Addressing Ethical Challenges in Public Health Practice. Los Angeles, CA: SAGE Publications Sage CA.

Baylis, Françoise, Nuala P. Kenny, and Susan Sherwin. 2008. A Relational Account of Public Health Ethics. Public Health Ethics 1 (3): 196-209.

Bernheim, Ruth Gaare, Phillip Nieburg, and Richard J. Bonnie. 2007. Ethics and the Practice of Public Health. In Law in Public Health Practice, ed. Goodman RA, 110-135. Oxford, NY: Oxford University Press.

Bielecki, Andrzej, and Sylwia Nieszporska. 2016. The Proposal of Philosophical Basis of the Health Care System. Medicine, Health Care and Philosophy 20: 1-13. https://doi.org/10.1007/ s11019-016-9717-2.

Buchanan, David R. 2015. Promoting Justice and Autonomy in Public Policies to Reduce the Health Consequences of Obesity. Kennedy Institute of Ethics Journal 25 (4): 395-417.

Bull, Susan, Phaik Yeong Cheah, Spencer Denny, Irene Jao, Vicki Marsh, Laura Merson, Neena Shah More, David Osrin Le Nguyen Thanh Nhan, Decha Tangseefa, and Douglas Wassenaar. 2015. Best Practices for Ethical Sharing of IndividualLevel Health Research Data from Low-and Middle-Income Settings. Journal of Empirical Research on Human Research Ethics 10 (3): 302-313.

Carter, Stacy M., Lucie Rychetnik, Beverley Lloyd, Ian H. Kerridge, Louise Baur, Adrian Bauman, Claire Hooker, and Avigdor Zask. 2011. Evidence, Ethics, and Values: A Framework for Health Promotion. American Journal of Public Health 101 (3): 465-472.

Chanda-Kapata, Pascalina, Nathan Kapata, Albertina Ngomah Moraes, Gershom Chongwe, and James Munthali. 2015. Genomic Research in Zambia: Confronting the Ethics, Policy and Regulatory Frontiers in the 21 st Century. Health Research Policy and Systems 13 (1): 1.

Childress, James F. 2015. Moral Considerations: Bases and Limits for Public Health Interventions. In Essentials of Public Health Ethics, eds. Ruth Gaare Bernheim, James F. Childress, Aalan L. Melnick, and Richard J. Bonnie, 21-43. Burlington: Jones \& Bartlett Learning, LLC, an Ascend Learning Company.

Childress, James F., and Ruth Gaare Bernheim. 2015. Introduction: A Framework for Public Health Ethics. In Essentials of Public Health Ethics, eds. Ruth Gaare Bernheim, James F. Childress, Aalan L. Melnick, and Richard J. Bonnie, 1-20. Burlington: Jones \& Bartlett Publishers.

Childress, James F, Ruth R. Faden, Ruth D. Gaare, Lawrence O. Gostin, Jeffrey Kahn, Richard J. Bonnie, Nancy E. Kass, Anna C. Mastroianni, Jonathan D. Moreno, and Phillip Nieburg. 2002b. Public Health Ethics: Mapping the Terrain. Journal of Law, Medicine \& Ethics 30 (2): 170-178.

Cockerham, William C. 2005. Health Lifestyle Theory and the Convergence of Agency and Structure. Journal of Health and Social Behavior 46 (1): 51-67.

Coughlin, Steven S. 2008. How Many Principles for Public Health Ethics. Open Public Health Journal 1: 8-16. 
Daniels, Norman. 2000. Accountability for Reasonableness : Establishing a Fair Process for Priority Setting is Easier Than Agreeing on Principles. BMJ 321 (7272): 1300-1301.

Daniels, N. 2008. Just Health: Meeting Health Needs Fairly. 1st Aufl. Cambridge: Cambridge University Press.

Daniels, Norman, and James Sabin. 1998. The Ethics of Accountability in Managed Care Reform. Health Affairs 17 (5): 50-64.

Daniels, Norman, and James E. Sabin. 2008. Accountability for Reasonableness: An Update. BMJ: British Medical Journal 337: a1850

Daniels, Norman, J. Bryant, R.A. Castano, O.G. Dantes, K.S. Khan, and S. Pannarunothai. 2000. Benchmarks of Fairness for Health Care Reform: A Policy Tool for Developing Countries. Bulletin of the World Health Organization 78 (6): 740-750.

Faden, Ruth, and Sirine Shebaya. 2016. The Stanford Encyclopedia of Philosophy: Public Health Ethics. Stanford: Metaphysics Research Lab, Stanford University.

Fox, Brion J. 2005. Framing Tobacco Control Efforts Within an Ethical Context. Tobacco Control 14 (Suppl 2): ii38-ii44.

Glanz, Jason M., Courtney R. Kraus, and Matthew F. Daley. 2015. Addressing Parental Vaccine Concerns: Engagement, Balance, and timing. PLoS Biology 13 (8): e1002227.

Greenhalgh, Trisha, and Richard Peacock. 2005. Effectiveness and Efficiency of Search Methods in Systematic Reviews of Complex Evidence: Audit of Primary Sources. BMJ 331 (7524): 1064-1065.

Health Council of the Netherlands. 2007. The Future of the National Immunisation Programme: Towards a Programme for all Age Groups. The Hague: Health Council of the Netherlands

Herington, Jonathan, Angus Dawson, and Heather Draper. 2014. Obesity, Liberty, and Public Health Emergencies. Hastings Center Report 44 (6): 26-35.

Hofrichter, R. 2003. Health and Social Justice: Politics, Ideology, and Inequity in the Distribution of Disease. San Francisco: Wiley.

Institute of Medicine. 2003. The Future of the Public's Health in the 21 st Century. Washington: National Academy Press.

Isaacs, David. 2012. An Ethical Framework for Public Health Immunisation Programs. New South Wales public health bulletin 23 (6): 111-115.

Jaffe, Harold W., and Tony Hope. 2010. Treating for the Common Good: A Proposed Ethical Framework. Public Health Ethics 3 (3): 193-198.

Jayasinghe, K.S.A., D. De Silva, N. Mendis, and R.K. Lie. 1998. Ethics of Resource Allocation in Developing Countries: The Case of Sri Lanka. Social Science and Medicine 47 (10): 1619-1625.

Kapiriri, Lydia, Ole Frithjof Norheim, and Douglas K. Martin. 2007. Priority Setting at the Micro-, Meso-and Macro-Levels in Canada, Norway and Uganda. Health Policy 82 (1): 78-94.

Kapiriri, Lydia, Ole F Norheim, and Douglas K. Martin. 2009. Fairness and Accountability for Reasonableness. Do the Views of Priority Setting Decision Makers Differ Across Health Systems and Levels of Decision Making? Social Science and Medicine 68 (4): 766-773.

Karen, M., and B. A. Meagher. 2011. Considering Virtue: Public Health and Clinical Ethics. Journal of Evaluation in Clinical Practice 17 (5): 888-893.

Kass, Nancy E. 2001. An Ethics Framework for Public Health. American Journal of Public Health 91 (11): 1776-1782.

Kenny, Nuala P, Susan B. Sherwin, and Françoise E. Baylis. 2010. Re-Visioning Public Health Ethics: A Relational Perspective. Canadian Journal of Public Health/Revue Canadienne de Sante'e Publique 101: 9-11.

Lee, Lisa M. 2017. A Bridge Back to the Future: Public Health Ethics, Bioethics, and Environmental Ethics. American Journal of Bioethics 17 (7): 5-12.
Lee, Lisa M, Celia B. Fisher, and Bruce Jennings. 2016. Revising the American Public Health Association's Public Health Code of Ethics. American Public Health Association 106: 1198-1199

Levine, Mark A., Matthew K. Wynia, Paul M. Schyve, J. Russell Teagarden, David A. Fleming, Sharon King Donohue, Ron J. Anderson, James Sabin, and Ezekiel J. Emanuel. 2007. Improving Access to Health Care: A Consensus Ethical Framework to Guide Proposals for Reform. Hastings Center Report 37 (5): 14-19.

MacDonald, Melanie. 1999. Resource Allocation in Integrated Delivery Systems and Healthcare Networks: A Proposed Framework to Guide Ethical Thinking. Healthcare Management Forum 12 (4): 24-29.

MacNaughton, Gillian. 2015. Human Rights Impact Assessment: A Method for Healthy Policymaking. Health and Human Rights Journal 17 (1): 63-75.

Marckmann, Georg, Harald Schmidt, Neema Sofaer, and Daniel Strech. 2015. Putting Public Health Ethics into Practice: A Systematic Framework. Frontiers in Public Health 3: 23.

Martin, Doug, and Peter Singer. 2003. A strategy to Improve Priority Setting in Health Care Institutions. Health Care Analysis 11 (1): $59-68$.

McGill, Natalie. 2015. APHA Section Creates Task Force to Revise Public Health Code of Ethics. The Nation's Health 45 (8): 17-17.

Menne, B., and R. Bertollini. 2005. Health and Climate Change: A Call for Action. BMJ 331 (7528): 1283-1284. https://doi.org/10.1136/ bmj.38684.496354.DE.

Nord, Erik. 1999. Cost-Value Analysis in Health Care: Making Sense Out of QALYs. Cambridge: Cambridge University Press.

Nuffield Council On Bioethics. 2007. Public Health: Ethical Issues. London, England: Nuffield Council.

Petricca, Kadia, and Asfaw Bekele. 2017. Conceptualizations of Fairness and Legitimacy in the Context of Ethiopian Health Priority Setting: Reflections on the Applicability of Accountability for Reasonableness. Developing World Bioethics 00: 1-8.

Petrini, Carlo. 2010. Theoretical Models and Operational Frameworks in Public Health Ethics. International Journal of Environmental Research and Public Health 7 (1): 189-202. https://doi. org/10.3390/ijerph7010189.

Petrini, Carlo, and Sabina Gainotti. 2008. A Personalist Approach to Public-Health Ethics. Bulletin of the World Health Organization 86 (8): 624-629.

Petrini, Carlo, and Gualtiero Ricciardi. 2015. Ethical Issues in Public Health Surveillance: Drawing Inspiration from Ethical Frameworks. Annali dell'Istituto Superiore di Sanità 51 (4): 270-276.

Powers, Madison, and Ruth R. Faden. 2006. Social Justice: The Moral Foundations of Public Health and Health Policy. 1st Aufl. Oxford: Oxford University Press.

Powers, Madison, and Ruth Faden, and Yashar Saghai. 2012. Liberty, Mill and the Framework of Public Health Ethics. Public Health Ethics 5 (1): 6-15.

Prainsack, Barbara. 2013. Taking Solidarity Seriously-Can it Help? In Justice \& Solidarity in Priority Setting in Healthcare. Brussels: Brussels Joint Initiative of the King Baudouin Foundation and the Belgian Advisory Committee on Bioethics.

Prainsack, B., A. Buyx, and Nuffield Council on Bioethics Staff. 2011. Solidarity: Reflections on an Emerging Concept in Bioethics. London: Nuffield Council on Bioethics.

Rajabi, Fateme, Hamid Esmailzadeh, Narges Rostamigooran, and Reza Majdzadeh. 2013. What must be the Pillars of Iran's Health System in 2025? Values and Principles of Health System Reform Plan. Iranian Journal of Public Health 42 (2): 197.

Resnik, David B. 2015. Food and Beverage Policies and Public Health Ethics. Health Care Analysis 23 (2): 122-133.

Riiser, Kirsti, Knut Løndal, Yngvar Ommundsen, Nina Misvær, and Sølvi Helseth. 2015. Targeting and Tailoring an Intervention for 
Adolescents Who are Overweight Some Ethical Concerns. Nursing Ethics 22 (2): 237-247.

Roberts, Marc J., and Michael R. Reich. 2002. Ethical Analysis in Public Health. Lancet 359 (9311): 1055-1059.

Rogers, Wendy A. 2004. Virtue Ethics and Public Health: A PracticeBased Analysis. Monash Bioethics Review 23 (1): 10-21.

Rozier, Michael D. 2016. Structures of Virtue as a Framework for Public Health Ethics. Public Health Ethics 9 (1): 37-45.

Ruger, Jennifer Prah. 2008. Ethics in American Health 2: An Ethical Framework for Health System Reform. American Journal of Public Health 98 (10): 1756-1763. https://doi.org/10.2105/ AJPH.2007.121350.

Shickle, Darren. 2009. The Ethics of Public Health Practice: Balancing Private and Public Interest within Tobacco Policy. British Medical Bulletin 91: 7-22

Shickle, Darren, Erica Richardson, Fiona Day, Christian Munthe, Albert Jovell, Heta Gylling, Rein Vos, Tuija Takala, Carlo Petrini, and Gaetano Torlone. 2006. Public Policies, Law and Bioethics: A Framework for Producing Public Health Policy Across the European Union. EuroPHEN: European Public Health Ethics Network. http://eprints.whiterose.ac.uk/100247/1/EuroPHENfullreport_libre.pdf

Stone, John R., and Groesbeck P. Parham. 2007. An Ethical Framework for Community Health Workers and Related Institutions. Family and Community Health 30 (4): 351-363.

Strech, Daniel, and Neema Sofaer. 2011. How to Write a Systematic Review of Reasons. Journal of Medical Ethics. https://doi. org/10.1136/medethics-2011-100096.

Swain, G. R., K. A. Burns, and P. Etkind. 2008. Preparedness: Medical Ethics Versus Public Health Ethics. Journal of Public Health Management and Practice 14 (4): 354-357. https://doi. org/10.1097/01.phh.0000324563.87780.67.

Tannahill, Andrew. 2008. Beyond Evidence-to Ethics: A DecisionMaking Framework For Health Promotion, Public Health And Health Improvement. Health Promotion International 23 (4): 380-390.
Ten Have, Marieke, Agnes Van Der Heide, Johan P. Mackenbach, and Inez D. De Beaufort. 2013. An Ethical Framework for the Prevention of Overweight and Obesity: A Tool for Thinking Through a Programme's Ethical Aspects. European Journal of Public Health 23 (2): 299-305.

Thomas, James C., M. Sage, J. Dillenberg, and V.J. Guillory. 2002. A Code of Ethics for Public Health. American Journal of Public Health 92 (7): 1057-1059. https://doi.org/10.2105/ AJPH.92.7.1057.

Thompson, Alison K., Karen Faith, Jennifer L Gibson, and Ross E.G. Upshur. 2006. Pandemic Influenza Preparedness: An Ethical Framework to Guide Decision-Making. BMC Medical Ethics 7 (1): 1.

Tiong, Wei Wei, and Gerald C.H. Koh. 2013. Ethical Considerations in the Review of Singapore's H1N1 Pandemic Response Framework in 2009. Annals of the Academy of Medicine, Singapore 42 (5): 246-250.

Torda, Adrienne. 2006. Ethical Issues in Pandemic Planning. Medical Journal of Australia 185 (10): S73.

Turoldo, Fabrizio. 2009. Responsibility as an Ethical Framework for Public Health Interventions. American Journal of Public Health 99 (7): 1197-1202.

Upshur, Ross E.G. 2002. Principles for the Justification of Public Health Intervention. Canadian Journal of Public Health/Revue Canadienne de Sante'e Publique 93: 101-103.

Verweij, Marcel F., and Hans Houweling. 2014. What is the Responsibility of National Government with Respect to Vaccination? Vaccine 32 (52): 7163-7166.

Wang, Yan-Guang. 1997. Aids, Policy and Bioethics: Ethical Dilemmas Facing China in HIV Prevention. Bioethics 11 (3-4): 323-327.

Wilcox, David. 1994. Community Participation and Empowerment: Putting Theory into Practice. London: RRA Notes.

Wilding, Ethan T. 2012. Framing Ethical Acceptability: A Problem with Nuclear Waste in Canada. Science and Engineering Ethics 18 (2): 301-313. 